\title{
Research on the Incentive Mechanism of Supplier in the Green Supply Chain Management
}

\author{
Baohua Shen ${ }^{1, a^{*}}$, Juan Jiang ${ }^{1, b}$ \\ ${ }^{1}$ Hangzhou Dianzi University, Xiasha Higher Education Zone, Hangzhou, 310018, Zhejiang \\ Province, China \\ ashenbaohua@hdu.edu.cn, bjiangjuan@hdu.edu.cn \\ *The corresponding author
}

Keywords: Green supply chain; Management; Supplier; Incentive mechanism; Construction

\begin{abstract}
The competition of market economy becoming global, protecting environment and low carbon economy receiving more attention from people, manufacturing industry with big pollution in order to seek development must strengthen the reform of logistics management mode and green supply chain is the best choice. The Scientific incentive mechanism among the members of the green supply chain play an important role in the smooth running of the whole supply chain. It's the key for green supply chain to choose the reasonable supplier, in the existing management mechanism, taking the factors of sustainable development into account, improving the construction of incentive mechanism for the supplier.
\end{abstract}

\section{The Meaning and Characteristics of Green Supply Chain}

The Meaning. Supply chain take the core enterprise as the focus, to strengthen the capital flow, logistics and information flow control at the same time, from Procurement of raw materials to the end of the process of selling the product to the consumer, as to connect suppliers, manufacturers, retailers and consumers into a network.

The Characteristics. Firstly, people facing resources, environment, population problem in today's society, green supply chain fully think about the top two problems In the process of the modern enterprise management mode striving to achieve the green enterprises of resource conservation, environmental protection.

Second, green supply chain is based on the traditional chain At the same time, emphasizing the management goal, paying attention to the environmental factors, to achieve the minimum cost of the supply chain and the greatest economic benefits.

Thirdly, the biggest feature of the whole process of green supply chain is closed, using the recycling technology, so that consumer goods in the end of its service life, once again join the supply chain system, to Let all or part of the parts to be recycled, so that it is conducive to reducing the adverse impact in the environment caused by the supply chain system, and promote the recycling of resources.

The Fourth, throughout the entire life cycle of the product from production to consumption, the concept of green runs through the whole process, while reducing the negative effect of the environment, reducing the cost of the whole supply chain, so that the green supply chain in the management is more practical, integrated. In addition, the idea of globalization sustainable development requires the supply chain to run through the end.

\section{The Importance of Suppliers in the Green Supply Chain Management}

The increasing competitions in the market makes the life cycle of the product shorten, and the most fundamental is to keep the sustainable development of the supply chain for enterprise cluster. Social, environmental and economic responsibility for sustainable development playing an important role, more and more enterprises pay attention to upgrade core competence but for noncore resources in general bought from suppliers. So supplier management become the key of enterprise and plays a 
fundamental role in whole enterprise supplier chain. Green procurement from suppliers directly affects the quality and cost of raw materials, and even determines the competitiveness of enterprises and the degree of green production. The control management levels for supplier affect the implementation of green procurement. Effectively encouraging suppliers changing suppliers' motivation, At the same time, the enterprise can run through the incentive mechanism, not only can improve the environmental benefits of the supplier but also can improve the performance of the manufacturer, what's more, enterprise can get more environment benefits.

Manufacturers to implement incentive mechanism can be from two aspects: first, Suppliers use incentive methods to stimulate suppliers to research and develop green products, enhance the green degree of raw materials, improve the market share of green products, to realize the sustainable development of the environment. Secondly, although the supplier has the ability to carry out green product development, but by the restrictions of the cost, had to raise product prices which may reduce sales. Manufacturers can cooperate with suppliers, appropriate compensation for suppliers to play an incentive role

The Importance of Supplier Selection can be Specific Performance in the Following Several Points. Firstly, enterprises realize green goal of protecting environment in the process of purchasing. Manufacturing enterprises are generally a system network composed of customers, suppliers and other organizational relationships. Enterprises purchasing behavior from suppliers determines the impact on the environment and for spirited environmental performance has an important role. For manufacturing enterprises, the protection of the environment is not only responsible for their own business, but also responsible for the supplier, so it is necessary to be included in the management system of the enterprise's environmental protection. Many suppliers are limited by the size of the enterprise, capital, etc. in order to ensure the smooth implementation of the green supply chain, manufacturers out of environmental management can provide corresponding support to the supplier, and supervise the implementation of the enterprise's green procurement, finally realize the enterprise's green procurement.

Secondly, Can reduce the cost of material purchasing and ensure the quality. Most of the quality control of the product is determined by the procurement process, and it is mainly controlled by the "upstream" suppliers. The upper quality of the product determines the quality of the enterprise, but also reduce the cost of goods inspection.in other words, If the enterprise can pay enough attention to strengthen the management of the supplier quality, then the quality of their products will be improved accordingly, and Enterprises should actively control the ex post control, to ensure the green production of enterprises

Thirdly, strengthen the enterprise's resources integration, improve the response ability. In economic activities, the enterprise as an open system bears the function of value conversion, through the exchange of materials and so on to promote the value-added products to meet the consumers needs. Facing the external environment, the management of suppliers can improve the ability of the market response. Enterprises can participate in the early material production, to seize the new product market. Manufacturers and suppliers share information, to improve the flexibility of enterprises, and promote the integration of resources.

\section{In the Green Supply Chain Management to the Supplier's Incentive Mechanism}

The Necessity of the Incentive Mechanism of the Green Supply Chain. Firstly, building incentive mechanism in the green supply chain management can guarantee the establishment of good strategic cooperation between enterprises to achieve horizontal integration, avoid short-term conflicts of interest, and build a cooperative and mutual trust relationship. The competition between the enterprise need incentive mechanism to ensure the interests sharing, based on Benefit and risk sharing.

Secondly, building the incentive mechanism of the green supply chain is actually promoting the smooth progress of the relationship between supply and demand. In fact, The relationship between supply and demand can be regarded as a principal - agent relationship, which is the relationship between the manufacturer and the market participants. For the client, the agent's action effect 
determines the size of the client's interests. So Incentive mechanism for the agent can regulate the agent behavior. In this way, we can coordinate the interests between the manufacturer and the supplier, becoming the construction of incentive mechanism to ensure the interests of the main body of the supply chain.

Economic Incentives of the Government. Firstly, preferential policies, the government plays the role of the accelerator in environmental optimization, responsible for creating a good system environment for the smooth progress of the green supply chain. To motivate raw material suppliers to improve the environmental protection, it is necessary for the government departments to provide the corresponding preferential policies, encourage suppliers to actively develop environmental protection materials, and promote the development of green production. For example, the government can reduce the bidding and agency costs of green product suppliers and the suppliers really get benefits, is bound to actively provide, develop green materials. The government can also reduce some tax, in order to enhance the supplier's environmental protection ideas. Especially for those to improve the efficiency of resource use, the supplier reducing the use of nonrenewable resources can use tax policy incentives

What's Specific can be based on its annual sales and give a certain percentage of relief. That can encourage enterprise to protect environment. Of course, the suppliers that waste nonrenewable resources such as oil, coal and other resources can give heavy taxes and warming. In addition, the government can also carry out corresponding subsidies, so as to create revenue for green product suppliers. Now, many suppliers have realized the importance of protecting environment, but limiting to own technology, capital and the consideration of risk Product innovation being overcautious. The government's subsidy policy can be appropriate to compensate the supplier to improve the cost of the product quality, and encourage the innovation ability .secondly, government support for procurement. Financial sector funding, government departments directly or indirectly buy green products, raw materials using the funds .but, what's different from the before is that suppliers must develop green products that meet the requirements of performance and cost, or technology in green supply management, The government support in the procurement, on the one hand can improve the efficiency of the funds use, on the other hand can stimulate the determination of innovative technology suppliers.

Technology Incentives of the Government. All enterprise do know the benefits of the green products in supply chain, but which need Higher technical content. At present, our country's product technology in green product is low and lacks of Innovative talents. The relevant departments should provide support and technical support to the suppliers so as to encourage them to produce and attack green raw materials. Specific practices are as follows: firstly, In R \& D, government departments can provide suppliers with innovative professional talents, to encourage the transfer of talent to suppliers, or provide relevant research and development technology, giving suppliers a helping hand. secondly when government help suppliers have the ability to produce green products, the key to put the real production, government departments can arrange professional people to give first spot guidance, supervision, to ensure that the smooth progress of the production of green products, production process optimization

Cooperation Incentive. Manufacturers and suppliers can better improve the environmental benefits with friendly cooperation. Evaluate the supplier's performance scientifically and reasonably, according to the specific situation, then, provide guidance for the supplier. Reasonable cooperation mechanism can make every link of enterprises to achieve maximum profit, reduce the waste of resources and Sincere and effective cooperation can make enterprises share the true and reliable information. Cooperation can be carried out from the following three aspects

Firstly, incentive in Alliance relationship. Manufacturers and suppliers forming a strategic alliance are conducive to optimizing the performance of all aspects in the supply chain. The basis of the two cooperation is the size of the transaction costs including parts: the cost of green raw material and environmental benefits. Strategic alliance relations can allow manufacturers to understand the supplier's cost information, which can be used to judge the level of environmental protection of raw materials products. Higher logistics and transportation costs also allow 
manufacturers and suppliers to share more information. Suppliers will also improve the enthusiasm of green products because of alliance cooperation.

Secondly, incentive in information sharing. Information sharing between manufacturers and suppliers can improve the operational level of supply chain. In the case of poor information sharing in the past, the supplier will have the opportunity to hide the cost of raw materials and the quality of the specific circumstances, Reducing the green degree in supply chain, because Manufacturers are limited to information constraints, cannot timely assess of product cost and quality levels. Information sharing between the two can provide real information of raw materials and products, so that enterprises in the chain timely grasp the market information, according to changes in market demand to provide green products.

Thirdly, incentive in Common $\mathrm{R} \& \mathrm{D}$ relationship. Green product technology innovation is the key factor to achieve green products, which is Related to the various enterprises in the supply chain.to achieve this goal, Manufacturers can work with suppliers to participate in the development of green products, suppliers according to the needs of the product updating production equipment, using the advanced production methods, to promote the spread of new products and technology in the chain, Through joining researching this way can cooperated share investment and risk, it is advantageous to the coordination relationship between the enterprises, green product development brought the economic benefits can make incentive effect on the partners.

Contract Incentive. When investment costs and the ultimate benefit are uncertain, contract incentives can reduce the risk of chain enterprises. According to economic incentives, getting profits in the process is why the supplier has to provide green raw materials. So in making the incentive contracts, should take the cost of training staff, green material design, packaging, quality supervision into account. While meeting special situation, for example, exchange rate fluctuations, etc. which can reduce the value of the product. At this time, manufacturers and suppliers have to develop relevant yield contracts, to jointly assume economic risks, give the appropriate compensation for suppliers.in case of unknowing market information, Contract incentive mechanism can properly coordinate, to ensure cooperation opportunities, supplier trying to provide raw materials which meet the requirements. What's more, it can also provide environmental protection materials by paying a certain performance salary to the supplier. So that, Suppliers whose $\mathrm{R} \& \mathrm{D}$ costs, quality costs are able to get compensation, will provide green materials. Finally, if supplier's and if materials satisfy environmental protection and manufacturer's requirements, and get go od reputation from consumers suppliers can get extra paying. This product quality incentive mechanism can encourage suppliers to improve awareness of environmental protection, incentives can effectively motivate suppliers.

\section{Conclusions}

In the current situation of environmental protection, enterprise of green supply chain is bearing moral hazard in the process of production cooperation. Only realizing the effective sharing of information, can we improve the mutual trust and cooperation among enterprises, promoting the efficient allocation of resources in the supply chain, improving the interests of enterprises and the competitiveness of the market. Building a reasonable and effective incentive mechanism can improve the supplier's environmental awareness and research and development of green raw materials. As the upper apartments of the green supply chain, the supplier's behavior directly affects the economic, social and environmental benefits of enterprises. This article provides some concrete measures to construct the incentive mechanism, and hope to provide help to the government departments and manufacturers.

\section{Acknowledgements}

Supported by the Department of Education of Zhejiang Province (No.Y201533713) 


\section{References}

[1] Cao jian, Wu Xiaobo, Zhou Gen GUI, based on product utility heterogeneity Green supply chain coordination strategy [J]. Computer integrated manufacturing system 2011, (6): 1279-1286.

[2] Zhuqinghua, Dou Yijie. Based on analysis of government subsidies for green supply chain management game model [J]. Journal of Management Sciences in China, 2011 (6): 86-95.

[3] Zhang Qiwei, green supply chain management research in manufacturing enterprise [D]. Chengdu: Sichuan University, 2005, 10.

[4] Bai Qing, discussion on the green supply chain management in China's manufacturing industry [D]. Guangzhou: Jinan University, 2008 